\title{
Ethno-Confessional Group of the Kryashens: Transformation of Identity and Modern Ethno-Cultural Processes
}

\author{
Tatiana A. Titova ${ }^{1}$, Vadim E. Kozlov ${ }^{1}$ \& Elena G. Guschina ${ }^{1}$ \\ ${ }^{1}$ Kazan (Volga Region) Federal University, Kazan, Russia \\ Correspondence: Elena Guschina, Kazan (Volga Region) Federal University, Kremlyovskaya Street 18, Kazan \\ 420008, Russia. E-mail: E-mail: egguschina@mail.ru
}

$\begin{array}{lc}\text { Received: April 14, } 2015 & \text { Accepted: April 20, } 2015 \quad \text { Online Published: April 27, } 2015 \\ \text { doi:10.5539/jsd.v8n4p260 } & \text { URL: http://dx.doi.org/10.5539/jsd.v8n4p260 }\end{array}$

\begin{abstract}
The research problem appears to be relevant due to the current mobility of ethnic and religious boundaries. It requires rapid response from the researchers for the purpose of obtaining objective knowledge and implementation of the received information into the public discourse. The aim of this study is to identify the current ethno-social and ethno-cultural needs that are present in the environment of the modern Kryashen population of the Republic of Tatarstan. The analyzed materials were obtained through the methods of large-scale survey, as well as in-depth interviews and focus groups. As a result of the data structuring, the elements of ethnic identity of the representatives of the Tatarstan Kryashen population were formalized and ranked. Furthermore, the author's interpretation of the studied phenomenon is introduced. The article can be useful for ethnologists, social and cultural anthropologists, political scientists, and representatives of the authorities and institutions responsible for the management of interethnic cooperation.
\end{abstract}

Keywords: the Kryashens, Tatars, identity, Orthodoxy, the transformation of identity, ethno-cultural practice, the invention of the tradition

\section{Introduction}

\subsection{The Relevance of the Problem}

Active discussions in the scientific journalism and media regarding the Kryashen population began in the end of the 1990s and reached its peak by the time of the 2002 census. Both Moscow and Tatarstan researchers, politicians, community leaders were involved in the discussion. Its main issue was whether to consider the Kryashens a separate ethnic unit, as it was suggested "below", or a sub-ethnic group of the Tatar people, as it was officially declared. Currently the problem of identity and ethno-cultural characteristics of Kryashen population became less politicized, thus expanding the opportunity for an objective assessment of the situation. The problem of perception of the Kryashens remains controversial. As it was suggested in our pilot study, the majority of the Kryashens do not have a clear identity and ideas about the boundaries of their group, ethno-cultural and linguistic qualities, etc. More often the nonethnic environment perceives the Kryashens as the local group of Tatar people with particular ethnic and religious traditions.

In the developing world, the processes of globalization are becoming specific to local communities. Against this background, there is a problem of evolution (and sometimes the transformation of identity, including the change of its hierarchy) and ethno-cultural conceptions and needs. The study of this problem has both academic and practical importance. Mosaic of identities, linguistic, cultural, religious and regional roles is today's social reality. The contraposition of identities (namely the identity and perception of the nonethnic environment) in the particular case, a kind of dialectic relations become a new plane for the research. Adjustments to these processes are contributed by the instrumental contexts, including the politics of recognition. Designated aspects are planned to be analyzed on the example of the Kryashen population of the Republic of Tatarstan.

\subsection{A Review of Research on the Topic}

In the scientific literature "Kryashen question" has several directions. Pre-revolutionary materials show that this period's focus was on the history of the community formation of the baptized Tatars and the religious processes among them, as well as educational activities, which attracted special attention of the missionaries (Mashanov, 1885; Mozharovskiy, 1880; Ilminskiy, 1913; Malov, 1866). At that time, the theory of the old baptized and the 
newly baptized Tatars was adopted in accordance with two periods of mass Christianization organized by the Russian government.

In the Soviet period the Kryashens were studied as a group with a stable identity. Within studies of Tatars developed by Kazan scientists from the National Academy of Sciences, a detailed description of the Kryashens, their language, material and spiritual culture was conducted (Vorobyov, 1929; Mukhametshin, 1977; Mametyev, 1999; Bayazitova, 1986).

By the start of the debate the society was dominated by a view that the Kryashens are the ethnographic group of Tatars. However, since the early 1990s, the Kryashen ethnocultural organization has gained strength. Its activity does not coincide with the rhetoric of regional authorities in the run-up to the Russian census of 2002, and it initiated a hot debate on "Kryashen issue" (Sokolov, 2002; Iskhakov, 2002; Belyakov, 2002).

Currently, there is a gap that still remains in the empirical studies of modern ethno-cultural practice of the Kryashens and structural issues of identity dynamics. The proposed project will contribute to the accumulation of empirical material and expansion of the information space.

\section{Materials and Methods}

\subsection{Purpose and Objectives of the Research}

This article presents a comprehensive analysis of identity, ethno-confessional and cultural realities of the modern Kryashen population of the Republic of Tatarstan. In regards of a common research problem, the set of questions covered is as follows:

- the degree of actualization and the hierarchy of identities among the studied population;

- knowledge of the census among bearers of this identity;

- attitudes to the authorities and their own symbol elite;

- ethnic and religious features (including the layer of the existing pre-Christian beliefs);

- the degree of ethnic and cultural proximity or remoteness with the Tatars, the Russians and other peoples living on the territory of the Volga region;

- modern ethno-cultural practices.

Scientific novelty of the presented materials is in their description of the social transformation that led to changes in the hierarchy of identities and ethno-cultural adjustment, as well as to the interfaith distance within the same ethnic community.

\subsection{Theoretical and Empirical Methods}

The study is based on the methodological principles of polyparadigm approach. In the context of our research there are two basic tenets of F. Bart's theory: first, the conclusion that the group membership determinant can be represented with socially-defined factors, which are based on the phenomenon of categorical attribution and not "objectively" existing cultural differences. Secondly, ethnic categories, both in the identification and in the process of referring others to certain ethnic groups, take into account not just the amount of objective differences, but only those of them which are regarded as significant by the individuals themselves.

This study was conducted through a combination of quantitative and qualitative methods: a large-scale survey using questionnaires, in-depth interviews, the method of focus groups, and the method of participant observation.

The sampling procedure was carried out incrementally in three stages:

1. The selection of the district was carried out in accordance with the materials of historical and ethnographic zoning.

2. The selection of the settlement was made on the administrative-territorial basis. According to the municipalities the localities of compact residence of the Kryashen population were selected.

3. Selection of respondents was carried out on the basis of common endonym "the Kryashens" according to the stratified quota (taken separately according to locality). The source: household books.

Under the proposed section the following range of issues is examined:

- the role of ethnic and religious factors in the identity matrix of the respondents;

- the degree of intra-group consolidation in the study group and the readiness for inter-ethnic cooperation;

- linguocultural orientation of respondents. 


\subsection{The Research Base}

During the study, 800 Kryashens were surveyed (349 men and 451 women). The study covered 8 administrative-territorial regions of compact settlement of the Kryashens. There were 10 interviews and 4 focus groups with the Kryashen representatives in the following administrative-territorial districts of the Republic of Tatarstan: Kaybitskiy, Laishevskiy, Rybno-Slobodskiy, Zainsk, Mamadysh, Chistopol, Kukmor, Yelabuga.

\section{Results}

\subsection{Characteristics of the Research Object}

These age-related characteristics of the sample have the following picture: $23.9 \%$ of respondents were aged from 18 to 30 years old (191 people), 49,4\% - from 31 to 55 years (395), 26,7\% - 56 and older (214).

The majority of respondents is married (officially registered in the registry office) - 52,9\%; married (registered according to the religious Canon) $-3,4 \% ; 14.2 \%$ of the respondents are registered both in the registry office and according to the religious Canon. Single respondents make $18.5 \% ; 8.4 \%$ of respondents are widowed. Let us remark here that the divorce is not common among respondents. The divorce rate is $2.5 \%$.

Education figures are as follows: $29.4 \%$ of respondents have got higher education, $38,3 \%$ have got secondary special education, $27.5 \%$ have got secondary education and $4.8 \%$ have got primary education. $21.8 \%$ of the respondents work in education, science, culture and art; $17,1 \%$ work in industry, construction and transport; $11.6 \%$ - in consumer services; $10 \%$ - in agriculture and forestry; $4.7 \%$ work in state administration bodies; $2.9 \%$ of the respondents work in law-enforcement agencies. $15.7 \%$ are the retirement pensioners, $5,1 \%$ are unemployed. The proportion of students is $8.7 \%$ of the surveyed people.

Most of the respondents are indigenous to the regions of interest $(74.6 \%)$, and the rest live in these areas for more than 10 years $(18.7 \%)$. The latter in their most are the immigrants from other settlements of the Republic of Tatarstan.

\subsection{Ethnic Identification of the Kryashens}

The respondents who participated in the study, show a strong identification with their own ethnic group. The identity feature of the Kryashens is their relationship with the religion, and linguistic characteristics.78.2\% of the respondents use the common endonym - "the Kryashens", 17.2\% use the term "the baptized Tatars". There are very few cases of those who consider themselves as Russian $-1,8 \% .1 .1 \%$ of the surveyed consider themselves as Tatars, $1.7 \%$ were undecided. Typically, this situation is associated with ethnic origin (descents from the mixed families) or with their own national mixed marriage.

Respondents generally do not subdivide themselves into the local groups of the Kryashens defined by the specialists (Fore-Kama, East Trans-Kama, Elabuga, West Trans-Kama, Molkeevo groups). The majority of respondents identified themselves as "just the Kryashens" (81,5\%), 12,8\% of the respondents found it difficult to define their identification.

In Rybno-Slobodskiy district $93 \%$ of the respondents consider themselves to be the Kryashens, $7 \%$ call themselves christened Tatars. In Laishevskiy municipal district $88 \%$ consider themselves to be the Kryashens, $1 \%$ - baptized Tatars, $5 \%$ - Tatars, 3\% - Russian, and 3\% found it difficult to answer the question. In Mamadysh district $88 \%$ identify themselves as the Kryashens, $10 \%$ of respondents consider themselves to be baptized Tatars, $2 \%$ were undecided. In Chistopol municipal district $84 \%$ of respondents consider themselves to be the Kryashens, $8 \%$ - christened Tatars, $6 \%$ - Russian, undecided - 2\%. In Zainsk municipal district $74 \%$ of the respondents consider themselves to be the Kryashens, $20 \%$ - christened Tatars, $1 \%$ - Tatars, 3\% - Russian, undecided - 2\%. In Kaybitskiy municipal district $27 \%$ of respondents consider themselves to be the Kryashens, $69 \%$ - baptized Tatars, $2 \%$ - Tatars, $2 \%$ - Russians. In Kukmor district $95 \%$ of the respondents consider themselves to be the Kryashens, $4 \%$ - christened Tatars, $1 \%$ undecided . In Yelabuga municipal district $75 \%$ identify themselves as the Kryashens, $19 \%$ - baptized Tatars, $1 \%$ - Tatars, $5 \%$ - undecided. (see diagram No. 1). The peculiarity of the situation in Kaybitskiy area, in our opinion, is in its geographical position and so far the ethno-cultural specificity of the surrounding population (borders with the Chuvash Republic). According to the respondents, the Tatar population of Kaybitskiy district is often called the Kryashen - Chuvashes because of Orthodox religion. Chuvash call them the Tatars according to linguistic affiliation. Cultural interaction of Chuvash and Kryashen population is observed in domestic ethno-cultural borrowing, ancient pagan rites and language features. At the same time, Kryashen population distance itself from the Tatar population.

In Kaybitskiy district most of the Kryashen population identifies themselves as "baptized Tatars", using endonym "baptized Tatars" and "the Kryashens" as synonyms. However, there is a view among informants that 
"Kryashens" and the ethnonym "baptized Tatars" are not identical.

"I am Kryashen. There is often the confusion, but we are Kryashens. The baptized Tatars are those who were Muslims, but they were baptized - the baptized Tatars, that's what they call themselves. And we are Kryashens. People often confuse it" (focus group. Bolshoye Tyaberdino village, Kaybitskiy district).

In the remaining districts the situation with identity is different. The majority of respondents use the term "the Kryashens" as a common endonym.

For example, the village of Tashkirmen is the only settlement in Laishevsky municipal district of Tatarstan, which is densely populated with the Kryashens. This fact allows residents to speak not only about the local culture, but also to use mythologemes of local historians that consider the modern Kryashen population here to have Mordovian roots. Hypothesis broadcasted by local historians is primarily based on the pre-Christian celebrations of spring and beginning of planting, which exist up to the present time and has parallels with the Mordovian population, as well as on the local dialect.

"They say that our chatter is very similar to that in Mordovia. There is a village in Tetyushi district, Mordovskiye Karatayi. It is possible that they're partially resettled, they could even sail here" (focus group, Tashkirmen village, Laishevskiy district).

In this region there is no problem with a choice between the ethnonyms "baptized Tatar" and "Kryashen"; second term is preferably and widely used.

"I am proud that I am Kryashen. We make our children to be aware that they Kryashens" (interview, woman, 42, Tashkirmen village, Laishevskiy district).

The respondents, who participated in the study, show a strong identification with their own ethnic group. Over half of the respondents (56.7\%) believe that it is "important" or "rather important" to feel like a representative of his/her people. For $9 \%$ of the respondents a sense of belonging to his/her people is not important.

"...indeed,it is very important. Traditions unite, although many people say that it is the religion that unites, I don't deny it, but it's not paramount. It is a linking and auxiliary factor. There are the people who are atheists, there are pagans who come from mixed families, but they all consider themselves to be the Kryashens. And there are a lot of them, and you needn't go to the Church for this. At foremost it's the tradition and the culture that links me with the nation..." (interview, expert, woman, 54, Kazan).

According to the study, the majority of the Kryashens refuse to call themselves "baptized Tatars"; they consider themselves to be the people with their own traditions, history, religion, culture, languages etc.

\subsection{The Role of the Census in the Process of Self-Identification of the Kryashen Population}

According to the Kryashens' opinion, a definite push to the actualization of self-identification was Russian census of 2002. This was an important moment, a turning point in many respects and a landmark in the development of the Kryashen community.

A number of our respondents remarked that during and after the census there was the circulation of rumors and stories, leading to doubts about the reliability of the records. Informants claim that "they have always called themselves Kryashens", and they dispute on the work of individual census takers. In their opinion, the latter had received the instruction to record them as the Tatars.

"Interviewer: What was your nationality record like in the census of 1989 ?

Respondent 1: The first time it was, we weren't asked. All were registered as the Tatars in 1989. And the second time we also were not asked, they wrote that we were Tatars and that's that. And when the census of 2010 was, then they wrote we were Kryashens.

Respondent 2: We are more conscious, we told them to write that we were Kryashens, and we watched, controlled, and others didn't; for old women they wrote... The census writer said," I'll write in pencil", we said, "Write with a pen, please" (focus group, Tashkirmen village, Laishevskiy district).

The similar situation was mentioned by the informants in other municipalities of the Republic:

"...The census writer told us to write that we were Tatar; and it is necessary to make a special column - baptized Tatar. People do not want to stir up the trouble, therefore, it's easier to write what the census writer says - the Tatar" (interview, man, 54, Molkeevo village, Kaybitskiy district).

"During school years our teachers convinced us that we were the Tatars... and it turned out that we are the Kryashens" (focus group, Zainsk). 
During and after the census of 2002 the Tatarstan scientists argued with Moscow experts about the need of using the term "baptized Tatars" for controversial groups. The Federal authorities' preference of the "Kryashens" term was explained with a policy point and also with the fact that "the Russian side did not want to admit the obvious thing - that national identity comes from the modern Tatar "high culture" (Iskhakov, 2002). The situation was further complicated by negative media coverage. What's more, the informants were confused by the attempts of those who acted as the scientists proving the invalidity of the Kryashens as a separate ethnos. The informants named some artists, politicians and other media persons as examples of "inefficiency" of referring themselves to the Kryashens

"...for example, when we were growing up we knew that someone had changed the name. For example, Nikolay Dunaev (Nail Dunaev), Grigoriy Rodionov (Garay Rakhim,) they all were Kryashens. They said, "If we didn't change our names, we wouldn't go far." It has always been that way" (focus group, Tashkirmen village, Laishevskiy district).

\subsection{Civil Identification of the Kryashen Population}

Exploring the hierarchy of the Kryashens' identities, we note that almost half of the respondents (45.4\%) consider themselves to be equally the citizens of the Russian Federation and Tatarstan; 18.9\% claimed about the priority of Russian identity; $13.5 \%$ of the respondents made their choice in favor of regional identity; $7.5 \%$ stated the importance of ethnic identity and $1.4 \%$ of respondents asserted the religious identity (see chart No. 2). According to this we can talk about the domination of the joint Russian-Tatar civic identity.

"I'm a tolerant person, a strong state is important for me. It is important for me to be a citizen of the Russian Federation as well as a resident of Tatarstan and the Kryashen" (interview, man, 77, Zainsk).

\subsection{Religious Identification of the Kryashen Population}

Confessional component is an important aspect of self-identification of the Kryashens. Religious factor acts as a marker of ethnic identity and a specifier of spiritual culture. $96.6 \%$ of respondents identify themselves with the Orthodoxy; $1.1 \%$ declared themselves either atheists or Muslims; and 2.3\% were undecided. $78 \%$ of respondents declared their freedom to satisfy their religious needs. The majority of respondents attend Church $(77,3 \%)$. The number of men and women is almost equal in the church parish. Young people aged 18 - 30 actively attend church. The share of young is even slightly higher $(80,1 \%)$ compared with the proportion of people of middle and older age categories (75,8 \%). Answering the question "How often do you attend Church?", 40.6\% of the respondents noted that they attend Church on religious holidays; $12.1 \%$ of the respondents attend Church monthly; $13.6 \%$ of the respondents do it occasionally.

«A lot of young people started attending the temple recently, especially on holidays. They baptize themselves and their children, they often get married in church. It's time to build new temples and renovate old ones in the villages" (interview, man, 52, Dyusmetyevo village, Mamadysh district)

According to our site studies, the informants often meant a visit to the temple as a problem because of the lack of parishes in the villages. They noted that there is only one Church for several villages, and in certain circumstances it is sometimes difficult to get to it. Another problem announced was that a Church service is held not on "Kryashen" language because of the absence of a Kryashen priest and specialized church literature.

"...there is the Bible on "Kryashen" language. A half only - Ilminskiy and his students translated it, and 70 years later, we started translating with the dictionaries of the previous century. This book is used in churches... indeed, there are troubles in the quantity of the sacred books and with the priests - we simply don't have them. Not enough people who would serve on "Kryashen"."(interview, expert, woman, 54, Kazan).

About half of respondents said that the service in "Kryashen" language is important; 16.1\% noted that don't care much about that.

"... I am convinced that the service should only be on the "Kryashen" language. "Kryashen" is like Church Slavonic for the Russians; so "Kryashen" for the Kryashens is the Church language" (interview, expert, woman, 54, Kazan).

In Staroye Tyaberdino village of the Kaybitskiy district few families still worship pagan gods.

"... my father believed in them, and so did I. We prayed to different gods - the sky, the rain, the sun, the earth. We, the village people, were grown in labour, and we were close to nature..." (interview, male, 57, Staroye Tyaberdino village, Kaybitskiy district).

This Kryashen group of Staroye Tyaberdino village (so-called unbaptized Kryashens or the pagan Kryashens), identify themselves as Kryashens, but have no relation to Orthodoxy and are not baptized. Agnates are strictly 
prohibited to be baptized in this group; however, there is relief for women. Pagan Kryashens still have their own cults, the private cemetery and the places of worship.

\subsection{Ethno-linguistic Processes in the Kryashens Environment}

While analyzing the linguistic-cultural component of Kryashen population we note that about $62,2 \%$ of respondents identified Tatar as their native language; $13.1 \%$ called "Kryashen", and about $8.5 \%$, defined the Russian language. A considerable proportion of respondents are in the ambivalent situation in regards of language. The language that is used by the Kryashens in everyday conversation is perceived as "Kryashen". And in fact the same language is used in the formal affairs, and the language of communication with the Tatars is Tatar. According to our observations, in every village there are precise local dialects, as well as borrowings from Chuvash, Mordovian and Russian languages.

It should be noted that currently the "Kryashen" language is presented primarily in pre-revolutionary religious literature; it is used in Church practice, but at the same time in some rural localities, it remains (is perceived) a language spoken in the home circle.

"So what is this language, this "Kryashen" - you should come to my class, listen to the kids talking. <...> They should know Tatar very well, they will never forget their own "Kryashen", it's in their blood. I speak "Kryashen" with my mom too" (focus group, Tashkirmen village, Laishevskiy district).

According to the survey, $90 \%$ of respondents said that they are free to satisfy their needs using their native language; 3.8\% have difficulties. They are the respondents who admit having a bad command of their own national language, using another spoken language in the communication environment, a different language in school, etc.

Considering the preference of language competence for the children and grandchildren, bilingual responses of different combinations were the most popular among the respondents. More than half of respondents (52.8 \%) believe that their descendants should learn the Russian and the Tatar languages first; $16.1 \%$ of the respondents preferred the Russian and European languages. According to our observations multilingualism among the Kryashens is considered to be the key to the stable success of the person.

\section{Discussions}

In the scientific literature "the Kryashen question" has several directions. Pre-revolutionary materials show that in this period the focus was on, first, the history of the community formation of the baptized Tatars and religious processes among them (Mashanova, 1885; Mozharovskiy, 1887) and, secondly, educational activities, which attracted special attention of the missionaries (Ilminskiy, 1913; Malov, 1866). The mentioned authors highlighted the question of "falling apart from the faith" and competition of Islam and Christianity in the Volga region (Dzherasi, 2013). At that time, the theory of the old baptized and the newly baptized Tatars was adopted in accordance with two periods of mass Christianization by the Russian government.

In the Soviet period the Kryashens were studied as a group with a stable identity. The 1926 census showed the Kryashen population, referred to "inaccurately designated nationalities" in "The List of Nationalities" with a total number of more than a hundred thousand people. The works of N. Vorobyov proved that "the newly baptized" Tatars almost completely returned to Islam, and modern Kryashens are descendants of "the old baptized" Tatars (Vorobyov, 1929). Within studies of Tatars developed by Kazan scientists from the National Academy of Sciences, a detailed description of the Kryashens, their language, material and spiritual culture was conducted (Mukhametshin, 1977; Mametyev, 1999; Bayazitova, 1986).

By the start of the debate the society was dominated by the view that the Kryashens are the ethnographic group of Tatars. However, since the early 1990s, the Kryashen ethnocultural organization has gained strength. Its activity does not coincide with the rhetoric of regional authorities in the run-up to the Russian census of 2002, and it initiated a hot debate. Russian anthropologist Sergei Sokolovskiy, who was a specialist in a working group during the preparation and conduct of the census, examined the "Kryashen issue" on the base of the legislation analysis, expert reports, press materials, and actual participant observation in his work "The Kryashens in the Russian Population Census of 2002" (Sokolovskiy, 2002). D. Iskhakov defended the regional point of view. He claimed that the separation of the Kryashens to a distinct ethnic unit is the idea of the Federal government with the only purpose to reduce the total number of Tatars (Iskhakov, 2002). During the post-Soviet decades, there have been several conferences uniting supporters of separation of the Kryashens, the results of which were published in the following collections of articles: "Ethnic and religious traditions of the Kryashens: history and modernity" (2001), "Modern Studies of Kryashens: status and prospects" (2005), "Ethno-historical and socio-cultural problems of self-identification of the Kryashens" (2008), "There are such people - the Kryashens: the problems of 
ethno-religious identification of the Kryashens" (2011). Rise of interest to the Kryashens after the census has given rise to new research. There were repeated references to the article by R. Belyakov "Of the Kryashens situation «in "Bulletins" of the Network of ethnological monitoring and conflicts early warning (Belyakov, 2002). The expeditions to the Kryashens were launched under the auspices of O. the Kazmina and E. Brakar (Moscow State University, Russia).In 2013 V. Ilizarova presented the thesis "Kryashens: Formation of Ethnic and Cultural Identity." The study of ethnic and cultural face of the Kryashens at the regional scale was conducted by Udmurt State University (the Republic of Udmurtia, Russia) and the Ufa Scientific Centre of the Russian Academy of Sciences (the Republic of Bashkortostan, Russia). Monographs on the national costume, folklore and traditional everyday culture of the Kryashens played an important role in the formation of knowledge on the tangible and intangible culture of the Kryashens (Suslova, 1993; Mukhmamedova, 2005). In recent years G. M. Makarov and the research center on the history and culture of the baptized Tatars (Kryashens) and nagaybaks from the Sh.Mardjani Institute of History, Academy of Sciences of the Republic of Tatarstan, proved their best in the area of the folk heritage research.

Currently, there is a gap that still remains in the empirical studies of modern ethno-cultural practices of the Kryashens and structural issues of identity dynamics. This problem was studied by our authoring group in the course of ethnographic and ethno-sociological studies of ethnic minority groups in the Republic of Tatarstan. These were undertaken in the framework of the scientific research work of the Department of archeology and Ethnology of the Kazan University. The study made it possible to examine thoroughly the mechanisms and factors of constructing of minority groups in the transformation of political and ethno-cultural space.

\section{Conclusion}

Summing up, we can note that:

- most respondents incline to use the common endonym "the Kryashens". The exception is the Kryashen population of the Kaybitskiy municipal district;

- the civil identity determination is dominated by "the citizens of the Russian Federation and Tatarstan";

- the religious factor in the Kryashens is a marker of ethnic identity. Both men and women actively take part in religious practices. In general the young people actively attend Church on Sundays and holidays, and implement the basic religious rites (christening, wedding, Eucharist, etc.);

- according to informants, the majority of respondents believe their native language is Tatar and recognize that "Kryashen" is the same Tatar language with local linguistic inclusions and household borrowings from languages of neighbouring ethnos. There are also local linguistic features in different localities; the Kryashens are in need of services on "Kryashen" Church language, as well as in the construction of churches and cultural sites.

\section{Recommendations}

The materials may have scientific and humanitarian and practical significance. First, the obtained results characterize actual ethno-cultural processes in the distinctive ethno-religious group. The latter interacts intensely with two groups of regional ethnic majority which represent different confessions. Secondly, the presented data can be used in cross-cultural studies of the phenomena of ethnic mobilization and ethnic consolidation of minority groups. All above mentioned causes potential interest in the subject studied - both from the point of view of the professional scientists and representatives of public institutions.

\section{Acknowledgments}

The work is performed according to the Russian Government Program of Competitive Growth of Kazan Federal University

\section{References}

Bayazitova, F. S. (1986). Govory tatar-kryashen v sravnitelnom osveschenii. Moscow, 247.

Belyakov, R. Yu. (2002). Kryasheny - povorot istoricheskoy sudby? Bulletin of the Network of Ethnological Monitoring and Conflict Early Warning, 41, 54-55.

Dzherasi, R. P. (2013). Okno na vostok: Imperiya, orientalizm, natsiya I religiya v Rossii. Moscow, 546.

Ilminskiy, N. I. (1913). O sisteme prosvescheniya inorodtsev i o Kazanskoy tsentralnoy krescheno-tatarskoy shkole. Kazan, 24.

Iskhakov, D. M. (1993) Etnograficheskie gruppy tatar Volgo-Uralskogo regiona (printsipy vydeleniya, formirovanie, rasselenie i demografiya. Kazan, 172. 
Iskhakov, D. M. (2002). Vzglyad na vserossiyskuyu perepis iz Tatarsrtana. Ab Imperio, 4, 235-249.

Malov, E. A. (1866). Statisticheskie svedeniya o kreschenykh tatarakh Kazanskoy i nekotorykh drugikh eparkhiy $v$ Volzhskom regione. Kazan, 81.

Mametyev, A. M. (1999). Traditsionnaya kultura nagaybakov (kryashen). The Museum of the XXI century: a look into the past and future: articles of the international research and training conference, 138-148.

Mashanov, M. A. (1875). Zametki o religiozno-nravstvennom sostoyanii kreschenykh tatar Kazanskoy gubernii Mamadyshskogo uezda. Kazan, 34.

Mozharovskiy, A. F. (1880). Izlozhenie khoda missionerskogo dela po prosvescheniyu kazanskikh inorodtsev c 1552 po 1867. Moscow, 264.

Mukhamedova, R. G. (2005). Narodny kostyum tatar-kryaschen. Kazan, 160.

Mukhametshin, Yu. G. (1977). Tatary-kryasheny: Istoriko - etnograficheskoe issledovanie. Moscow, 184.

Sokolivskiy, S. V. (2002). Kryasheny vo Vserossiyskoy perepisi naseleniya 2002 goda. Moscow, 247.

Suslova, S. V. (1993). Traditsionnaya odezhda molkeevskikh kryashen. Molkeevo Kryashens, 66-68.

Tishkov, V. A. (1997). Ocherki teorii I politiki etnichnosti v Rossii. Moscow, 532.

Vorobyov, N. I. (1929). Kryasheny i tatary. Nekotorye dannye po sravnitelnoj kharakteristike byta. Work and economy, 5, 12.

\section{Copyrights}

Copyright for this article is retained by the author(s), with first publication rights granted to the journal.

This is an open-access article distributed under the terms and conditions of the Creative Commons Attribution license (http://creativecommons.org/licenses/by/3.0/). 